\title{
Longing to re-inhabit public architecture and civic space
}

In arq 24.2, we reflected on the measures taken to lock down societies in response to the Coronavirus pandemic and the accompanying forfeiture of civic space - including the closure, or emptying out, of the streets and rooms of the city and its associated theatres, music venues, community centres, libraries, restaurants, bars, museums, galleries, pools, gyms, stadia, and sports fields. As lockdowns continue - in arq's British domicile and much of the world, with the way out still uncertain - so the accompanying sense of loss continues. This issue of arq considers the widespread, pent-up longing to properly inhabit public architecture and civic space once again.

Jun-Yang Wang scrutinises Hua Li's Xinzhai Coffee House in China's Western Yunnan Province, studying how site, programme, and tectonic expression were imagined together there (pp. 314-326). He reads the building in relation to Göttfried Semper's nineteenthcentury theories about cladding, understanding it in terms of 'an almost atavistic love of craft that engenders a commitment to assert the loadbearing meaning of masonry'. Wang revels in the building's exaggeration of mass, and articulation in section, to achieve spatial effects. The paper offers a vicarious opportunity to engage with an architecture of heightened atmosphere at a time when real experiences are so restricted.

The absence of occupation is central to Claudia Pérez-Moreno's discussion of midtwentieth-century sculptor Jorge Oteiza, who Rafael Moneo asserted made a major contribution to architecture (pp. 343-352). Otieza was concerned with 'emptying', with physical subtraction from mass, 'taking away from a material block that which is not required'. Appositely, understood from our current situation, this was theorised as 'desocupación', or 'de-occupation': a kind of asceticism that simultaneously became a way to engage.

Meanwhile, Mirjana Lozanovska and Akari Nakai Kidd examine deindustrialisation in Geelong, Victoria, Australia and the re-use of the Ford factory there (pp. 353-368). They recount projects engaging with the building, its former processes and worker stories. Igor Marinović studies 'incremental housing' in Chile, specifically the Lo Espejo condominium (pp. 369-378). This housing involves a 'build-as-you-go' process where reduced upfront capital costs result in partially completed houses that get completed through self-build. Marinović proposes that inhabitants should be educated about inhabitation and building skills. In this light, it's possible to reflect on the value of community architectural education as we emerge from lockdown, to help people to engage once more with public 
buildings and civic space. This is reflected in exhibition materials produced in 1945 in the UK by Ernö Goldfinger, titled 'Planning Your Neighbourhood', recounted by Stuart Mills (pp. 327-342). These materials echoed various similar British endeavours, at that time, encouraging people to re-imagine city spaces in radically new and different ways after the destruction and trauma of war.

Concluding this issue, Johnny Rodger revisits Rem Koolhaas's ideas about Junkspace (pp. 383-386). 'For months we have been locked out of Junkspace', he writes, 'so, who's complaining?' 'Who would say that they truly missed their daily passage through the endlessly stale air of check-in desks, departure gates, and duty frees at the airport', Rodger argues provocatively, 'the epic journeys through low ceiling corridors and passageways of railway terminals and subway stations; and the blinding hallucinatory proliferation of brands and franchises in malls?'

The institutions of architectural culture have also responded to changed times, shifting their exhibitions and lecture programmes online. Aurel von Richthofen reviews the digital version of Stanislas Chaillou's 'Artificial Intelligence \& Architecture' exhibition held at the Pavilion de l'Arsenal, Paris (pp. 379-381), while Owen Hopkins sends a letter from the museum in lockdown (pp. 387-391). The desire to return to galleries in real life feels just as potent as our longing to properly inhabit architecture and civic space again. 